\title{
BELIEF STRENGTH IN LOW-PRICED PRODUCT CONSUMPTION EXPERIENCE
}

\author{
Ignasius Heri Satrya Wangsa (ignherisw@gmail.com) \\ De La Salle University, Malaysia
}

\begin{abstract}
This research aims to identify emotional values within low-priced product attractiveness context by employing scientific rationalization on belief strength in consumption experience. Comparison among two price-benefit regimes i.e. "cheap is the best" and "expensive is the best" is made. Belief strength is applied to explore new dimension in low-priced product consumption experience research.
\end{abstract}

Keywords: belief strength, low-priced product attractiveness, low-priced product consumption experience

\section{INTRODUCTION}

Most products have been equipped with attractive element or "cosmetics" to trigger buying behavior. In many cases it has shown that buying behavior is not the end. Some start developing "eye-catching" elements to mainly attract attention. Therefore, the cosmetical dimension might lead to be effective tool to draw attention which at the end would contribute benefit to consumer's perception. This drawing attention is consumption experience which has become the product itself. In other words, consumption experience does not start from consuming the tangible appearance rather it begins with consuming the intangible representation (of product).

The reality of technology has been offering a very sophisticated way to create manipulation of image. Indeed, in certain degree, image manipulation creativity leads to be a significant factor contributing to emotion. In the context of low-priced product attractiveness, emotional values lay in consumer's rationality on the connection between low price and high quality. Irrationality and emotion can potentially go to reciprocal direction. However, in most cases that emotion is the root for irrationality, people have become so irrational when they fail to manage emotion.

Based on the above background, three areas are covered in this research. First, belief strength (Smith \& Swinyard, 1982) in which consumer's decision has been made in an extreme and subjective way. Belief strength may create barrier of consumer's access to think rationally toward the product. Consumer brings himself to the extreme point referring to perception of the highest degree of benefit such as in the idea of symbolic price "high price is the best" and rationalization of "less for more". This perspective leads to two different orientations of price i.e. price as major indicator to product value (high price represents high quality) and price as the main reason for relative thinking (low price is relative to more savings). In the symbolic price, high price would always have high benefit (e.g. for social acceptance) and becomes the only main indicator for high quality. In the opposite way, low price is always beneficial for "investment" i.e. creating more savings. Second, experience of surprising moment (moment of truth) which involves emotion. Third, responses of rejection or appreciation. 
This research is trying to integrate the construct of belief strength with experience of surprising moment (moment of truth) which involves cognitive activity and responses of rejection or appreciation. In belief strength of savings benefit (low price for high quality or benefit) the perception of "cheap is the best" most likely happens. Perception of "expensive is the best" happens in belief strength of social benefit (high price for high quality or benefit). In both context of belief strength, consumers' experience of surprising moment produces response of appreciation when there is no gap or distance between consumers' expectation and product performance. Response of rejection happens if product can not meet with expectation.

\section{THEORETICAL FRAMEWORK}

Price has become main object in marketing research as its ability to explain market behaviour. Prices as market instrument is used to allocate scarce resources and constrain desires and coordinate actions. In practical aspect, contribution of price-related research is to know the social phenomena of human behaviour, specifically to structure sociological theories (Becker 1976:5).

Context of price-consumer connectivity brings consumer as the main actor in price consumption process in which consumption as expressing the making use of price or acquisition of price utility (see Nassar Senior in Becker).

The value and utility designate the worth that a person attaches to a good or service. They are not inherent in the good or service but they are inherent in regard a person or people have for it. Likewise, attachment or having to a good or service means that it has worth (and, at the same time, value and utility). Possession which leads to a satisfaction means that a good or service has worth i.e. value and utility.

There is emotional dimension of value and utility as mentioned by Fabricky (1998). First, the range of emotion and user's evaluation of the utility. The utility that available good or service may have in the mind of a prospective user may be expected to be such that his desire for them will range from abhorrence, through indifference, to intense desire. Second, most things that have utility for an individual are physically manifested. Price has utility (for an individual) with physical aspects in "realization through emotional senses". Hence, the physical aspects of price might be "creation of certain emotion". Third, the wants of people are motivated largely by emotional drives and tensions, and to a lesser extent by logical reasoning processes. Krug \& Cass (1989) mention that emotion, behavior, thinking or somatic responses are manifestation of disturbance in affect. Emotion is more transient, less pervasive, more directly reflected in physiological responses, and more specific in ideational content. In certain condition, emotion can also be very sensitive or emotional liability i.e. emotional responses in excess of what is usually anticipated even with minor stimuli.

Consumer's response to value and utility involves his cognitive actity. In other words, there is cognitive component of response (see Smith \& Swinyard, 1982). Cognitions have been measured as recall or recognition of the product or its attributes. Fishbein and Ajzen has introduced analysis of cognitive variable using diagnostic value of expectancy-value model to identify belief strength. It is the magnitude of the subjective probability of association between the attribute and the object. Increasing belief strengths could contribute to overall 
affect in a nonlinear manner by raising total affect in some multiple of the increase in belief strength. (Smith \& Swinyard, 1982).

Cognitive refers to thinking activity which is a process of conceptualization, construction, manipulation, and communication of symbols. Product of thinking activity is thought manifested in categories of language (Benveniste in Lechte, 1994). Thought contains ideas of reference. Any events interpreted as having special personal meaning can be part of ideas of reference (see Krug \& Cass, 1989:15).

\section{METHODS}

Methodological framework for this research is derived from integration of three methods of knowing and acquiring knowledge namely tenacity, rational and empirical (Gravetter \& Forzano, 2009). Method of tenacity involves holding on to normative idea of price and product quality relationship. Rational method is logical reasoning of positive direction in price and product quality relationship. While empirical method is applied by qualitativequantitative approach to know the phenomena of belief strength in low-priced product consumption experience.

In this research, belief strength is used to know the degree of emotion with five Likert-scales as the tool. Two extreme points or values of 1 (=strongly disagree) and 5 (=strongly agree) in the Likert-scale are chosen as the indicator for belief strength. In addition, belief strength may potentially happen when the sample mean value is close to those points or values as it is indicated by the lower value of sample mean difference. Belief strength may not potentially happen when the sample value is far from the extreme points of 1 (=strongly disagree) and 5 (=strongly agree) as it is indicated by the greater value of sample mean difference.

Participants and respondents of this research are Third Year College students who are taking Marketing Management class. They are assigned to make composition entitled "My Story of Best Offer Product" (Wangsa 2011:229-251). One of the best composition is used by the author for qualitative research. The author applies integration of qualitative and quantitative approach. It is built upon the very practical need to develop best possible methodology for the issue of low-priced product consumption experience (Carson et al. 2001: 204). First, narrative analysis which includes paragraph and sentencial analysis. Content analysis for each paragraphs and sentences is used to find and identify components of social benefit in highprice regime and components of savings benefit in low-price regime. Second, quantitative approach is applied to measure strength of tendency or direction for the two regimes.

\section{RESULTS AND DISCUSSION}

The following is a composition entitled "My Story of Best Offer Product" by AA (18 years old).

Paragraph analysis

Paragraph-1 (P-1)

The last time that I experienced to buy a "best offer" product was yesterday, June,30,2012. A best offer is something that a buyer and seller can achieve through exchange or negotiations that satisfies both parties Me and my family went to 888 china town square Bacolod yesterday. We were supposed to buy new CDs but nothing of my interest was there. We strolled around and I was getting bored but then I saw something that attracted me. A store 
full of Iphone casings. I bought myself a new casing for my Iphone. At first I didn't like anything but scanned my eyes around and I found a cute little case. It was a simple metallic casing. It had few designs but it looked cute and was very colorful. I know that it is not branded but the designs looked so elegant and neat that I would've considered it as one. At first it was sold for 500 pesos but after a few bargaining with the store manager, I got it for 350 pesos. It was a good bargain for me because I saved 150 pesos. (AA/P-1)

General message: Memorable event as the participant can easily recognize the date, place, product and price. Expression of mood can easily be seen. (AA/P-1/GM)

Specific message: The participant is able to express satisfaction because of a good bargain. (AA/P-1/SM)

Paragraph-2 (P-2)

The product is not at all disappointing except that it had little scratches at the sides. It actually looked like an original, if someone showed it to me I would've considered it as an original casing. It's not as clean as the original casings found on Istore but it was enough for me. I think that it is a "best offer" because it had great quality for a low price. It had great attractive designs only for a cost of 350 pesos. It should've been 500 pesos but they offered it to me for 350 pesos. (AA/P-2)

General message: Definition of best offer product (AA/P-2/GM)

Specific message: Details on high quality for a low price (AA/P-2/SM)

Paragraph-3 (P-3)

I didn't get the sense of originality from the product. Of course it was just a mere copy of the original designs from Istore but at least I got it for a low price and really, it just looked the same. I was happy to have the product that most people couldn't even afford to buy if it was original. That product was just a copy but it says it all. It had the same features and quality as the original product. Really, you couldn't tell the difference I got to save a lot of money from buying it too. It was a benefit for me more than a cost because I got to have it for a low price. It was cute and looked attractive too. It had great designs and it was only for a low price. I couldn't imagine I could buy something as a amazing as that for a low price. I didn't even think they could a copy of the original and still look like an original. I got the benefit of using it. It was sturdy enough to hold my phone and I think it would last long if I'd just take care of it. (AA/P-3)

General message: Expression of satisfaction (AA/P-3/GM)

Specific message: Reasons for satisfaction i.e. social and money/saving benefit (AA/P-3/SM)

Paragraph-4 (P-4)

From seeing the original cases before at the Istore, I realized that maybe they are over pricing it. Something as little as a iphone cover or casing should not cost that much like 2000 pesos. That is just ridiculous. Why then at 888 it only cost 300 pesos? It looks exactly the same; $i$ bet it's even made from the same materials. Some things are just meant to be bargained. Some things are overpriced. I realized that we people should be smart in buying our products. Products like this shouldn't cost us that much. Why buy an Iphone case that costs 1000 pesos or more, when we could get it for as low as 200-300 pesos. Of course $i$ am not suggesting we buy pirated products or products that are just copies, I'm just saying that store owners should adjust their prices fairly and right so that we buyers wouldn't question 
them and it is also our right to know and pay the exact fair price for whatever product we buy.

General message: Expression of justice for the right price (AA/P-4/GM)

Specific message: Conclusion or judgment of unfair and incorrect price (AA/P-4/SM)

Paragraph-5 (P-5)

I recommend store owners to be more fair in giving reasonable prices. Over pricing is to put too high a price or value on everything. It is never right. I suggest they adjust their prices fairly so that more people would be capable of buying their products. Of course i recommend high quality products too so that more customers would be satisfied and delighted. They might even be willing to buy different products or new products to you because then they'd develop a trust in your company. I also recommend people to be thorough when buying their products. They must be wise in picking out low-priced-high quality products. It would benefit them greatly like it did to me. Some low-priced products are also low quality products so people need to really open their eyes and see. They must be observant with the things they buy like at some point, there are some products that are highly priced but posses a very low quality features. We must pick those that are either low or medium priced products with high quality, that way we can say that we had the best offer products of our life.

General message: Recommendation, suggestion and conclusion for best offer product (AA/P$5 / \mathrm{GM})$

Specific message: Rationalization on the connection between price and product quality (AA/P-5/SM)

Discussion for Paragraph analysis:

The composition contains five paragraphs. The participant is able to express idea on best offer product using her past experience. The experience itself is memorable as she is able to recall specific date (AA/P-1/GM). She has expressed positive experience on lower or cheaper price either for social or savings benefit (AA/P-3/SM). Quality is also about opportunity to have good bargain (AA/P-1/SM), and nothing to do with high price. High price is easily perceived as unfair and incorrect (AA/P-4/SM).

$\underline{\text { Sentence analysis }}$

Paragraph-1 (P-1)

Sentence-1 (P-1/S-1): The last time that I experienced to buy a "best offer" product was yesterday, June,30,2012. (specific time)

Sentence-2 (P-1/S-2): A best offer is something that a buyer and seller can achieve through exchange or negotiations that satisfies both parties. (definition of best offer)

Sentence-3 (P-1/S-3): Me and my family went to 888 china town square Bacolod yesterday. (action, specific place/store)

Sentence-4 (P-1/S-4): We were supposed to buy new CDs but nothing of my interest was there. (mentioning product, mood) 
Sentence-5 (P-1/S-5): We strolled around and I was getting bored but then I saw something that attracted me. (from dissatisfaction to attention)

Sentence-6 (P-1/S-6): A store full of Iphone casings. (product atmospheric)

Sentence-7 (P-1/S-7): I bought myself a new casing for my Iphone. (independence, maturity, self-sufficient)

Sentence-8 (P-1/S-8): At first I didn't like anything but scanned my eyes around and I found a cute little case. (mind flow from nothing to something)

Sentence-9 (P-1/S-9): It was a simple metallic casing. (description)

Sentence-10 (P-1/S-10): It had few designs but it looked cute and was very colorful. (description with emotion)

Sentence-11 (P-1/S-11): I know that it is not branded but the designs looked so elegant and neat that I would've considered it as one. (description with emotion)

Sentence-12 (P-1/S-12): At first it was sold for 500 pesos but after a few bargaining with the store manager, I got it for 350 pesos. (success of bargaining)

Sentence-13 (P-1/S-13): It was a good bargain for me because I saved 150 pesos. (emotion of success of bargaining)

Discussion for Paragraph-1:

Paragraph-1 contains 13 sentences. Expression of emotion can be found in P-1/S-4, P-1/S-7, $\mathrm{P}-1 / \mathrm{S}-8, \mathrm{P}-1 / \mathrm{S}-10, \mathrm{P}-1 / \mathrm{S}-11$. There is "nothing" that is attractive and relative to expectation (P-1/S-4). There is not enough set of object that can meet with participant's expectation. The participant has certain criteria but it can not be fulfilled. Internally, there is an emotion of proud to be independent (P-1/S-7) which is relative to financially sufficient. Emotion is also about sudden flow of awareness from "nothing to something" (P-1/S-8) which is actually driven by active participation "I scan my eyes around". Design may trigger earlier attraction which could bring participant to another more emotional part (P-1/S-10). Participant is also rational enough to know that product is unbranded $(\mathrm{P}-1 / \mathrm{S}-11)$ but other product element i.e. the design is able to produce emotion. Emotion is also related to participant's winning of good bargain (P-1/S-13).

Paragraph-2 (P-2)

Sentence-1 (P-2/S-1): The product is not at all disappointing except that it had little scratches at the sides. (tolerable dissatisfied, acceptance)

Sentence-2 (P-2/S-2): It actually looked like an original, if someone showed it to me I would've considered it as an original casing. (biased original)

Sentence-3 (P-2/S-3): It's not as clean as the original casings found on Istore but it was enough for me. (tolerable dissatisfied, acceptance) 
Sentence-4 (P-2/S-4): I think that it is a "best offer" because it had great quality for a low price. (definition of best offer)

Sentence-5 (P-2/S-5): It had great attractive designs only for a cost of 350 pesos. (attractivenes for low price)

Sentence-6 (P-2/S-6): It should've been 500 pesos but they offered it to me for 350 pesos. (attractiveness for low price)

Discussion for Paragraph-2:

Paragraph-2 contains six sentences which mostly mention positive orientation for low price. Loyalty to low price is shown by tolerable dissatisfaction or acceptance for product defects. Acceptance for product defect is represented by words/phrases such as "scratches" $(\mathrm{P}-2 / \mathrm{S}-1)$, "looked like an original" (P-2/S-2), and "not as clean as the original casings" (P-2/S-3). Emotion on "attractive design" equals to appreciation for the best low price "only for 350 pesos" (P-2/S-5). Quality is about low price. Participant's values "little" defect as tolerable which has no impact to her defining "great " quality product (P-2/S-4). Low price policy from the seller is quite effective to win the heart of consumer $(\mathrm{P}-2 / \mathrm{S}-6)$.

Paragraph-3 (P-3)

Sentence-1 (P-3/S-1): I didn't get the sense of originality from the product. (acceptance, tolerance)

Sentence-2 (P-3/S-2): Of course it was just a mere copy of the original designs from Istore but at least I got it for a low price and really, it just looked the same. (tolerance for fake product as long as it is cheaper)

Sentence-3 (P-3/S-3): I was happy to have the product that most people couldn't even afford to buy if it was original. (social benefit)

Sentence-4 (P-3/S-4): That product was just a copy but it says it all. (acceptance, tolerance)

Sentence-5 (P-3/S-5): It had the same features and quality as the original product. (defending, justification for fake product)

Sentence-6 (P-3/S-6): Really, you couldn't tell the difference I got to save a lot of money from buying it too. (assurance, justification for fake product)

Sentence-7 (P-3/S-7): It was a benefit for me more than a cost because I got to have it for a low price. (attractiveness for low price)

Sentence-8 (P-3/S-8): It was cute and looked attractive too. (justification the best for low price)

Sentence-9 (P-3/S-9): It had great designs and it was only for a low price. (attractiveness for low price, repetition for $\mathrm{P}-2 / \mathrm{S}-5$ )

Sentence-10 (P-3/S-10): I couldn't imagine I could buy something as a amazing as that for a low price. (success buying for low price) 
Sentence-11 (P-3/S-11): I didn't even think they could a copy of the original and still look like an original. (defending, justification for fake product)

Sentence-12 (P-3/S-12): I got the benefit of using it. (re-assurance for the best buying decision)

Sentence-13 (P-3/S-13): It was sturdy enough to hold my phone and I think it would last long if I'd just take care of it. (complimentary for the best buying decision)

Discussion for Paragraph-3:

Paragraph-3 contains thirteen sentences. Low price offers great advantage specially when it is relative to physical appearance. Emotional expressions on physical appearance such as "cute, attractive" are commonly used (P-3/S-8). Belief strength can also be found in the way participant's defending or making justification that fake product is accepted as long as it is cheap. However, participant seems to be "very tolerable" when she expresses the using of fake product. This can be seen from the sentences that she would like to express such as in P3/S-5 and P-3/S-11. In other words, she would like to say in her own perception that the product is still "completely original". Product's physical appearance in complement with low price seems to be the successful factor to win the heart of participant.

Paragraph-4 (P-4)

Sentence-1 (P-4/S-1): From seeing the original cases before at the Istore, I realized that maybe they are over pricing it. (sensitivity for high price)

Sentence-2 (P-4/S-2): Something as little as a iphone cover or casing should not cost that much like 2000 pesos. (expression of upset, evaluation)

Sentence-3 (P-4/S-3): That is just ridiculous. (expression of upset)

Sentence-4 (P-4/S-4): Why then at 888 it only cost 300 pesos? (attractiveness for low price)

Sentence-5 (P-4/S-5): It looks exactly the same; I bet it's even made from the same materials. (defending, justification for fake product)

Sentence-6 (P-4/S-6): Some things are just meant to be bargained. (sensitivity for high price)

Sentence-7 (P-4/S-7): Some things are overpriced. (sensitivity for high price)

Sentence-8 (P-4/S-8): I realized that we people should be smart in buying our products. (recommendation)

Sentence-9 (P-4/S-9): Products like this shouldn't cost us that much. (evaluation)

Sentence-10 (P-4/S-10): Why buy an Iphone case that costs 1000 pesos or more, when we could get it for as low as 200-300 pesos. (attractiveness for low price) 
Sentence-11 (P-4/S-11): Of course I am not suggesting we buy pirated products or products that are just copies, I'm just saying that store owners should adjust their prices fairly and right so that we buyers wouldn't question them and it is also our right to know and pay the exact fair price for whatever product we buy. (justification of fake product for external purposes using price unfairness)

Discussion for Paragraph-4:

Paragraph-4 contains eleven sentences. Participant's sensitivity and critical evaluation on high price in P-4/S-1, P-4/S-6, and P-4/S-7 are used to justify for her best decision (lowpriced fake product). She defends her best decision by giving recommendation to be more critical on unfairness of price. She seems to be reluctant to expose herself that she is favor to low price. Her advocacy for price fairness is just for social or external purposes so that her best decision (for low price) can easily be "legalized" or socially accepted.

Paragraph-5 (P-5)

Sentence-1 (P-5/S-1): I recommend store owners to be more fair in giving reasonable prices. (comment on price unfairness)

Sentence-2 (P-5/S-2): Over pricing is to put too high a price or value on everything. (general meaning for over pricing)

Sentence-3 (P-5/S-3): It is never right. (comment on price unfairness)

Sentence-4 (P-5/S-4): I suggest they adjust their prices fairly so that more people would be capable of buying their products. (suggestion for price unfairness)

Sentence-5 (P-5/S-5): Of course I recommend high quality products to so that more customers would be satisfied and delighted. (high quality corresponds with satisfaction)

Sentence-6 (P-5/S-6): They might even be willing to buy different products or new products to you because then they'd develop a trust in your company. (the importance of trust)

Sentence-7 (P-5/S-7): I also recommend people to be thorough when buying their products. (recommendation for smart buying)

Sentence-8 (P-5/S-8): They must be wise in picking out low-priced-high quality products. (smart buying for low-priced and high quality product)

Sentence-9 (P-5/S-9): It would benefit them greatly like it did to me. (personal experience for smart buying)

Sentence-10 (P-5/S-10): Some low-priced products are also low quality products so people need to really open their eyes and see. (relationship between price and product)

Sentence-11 (P-5/S-11): They must be observant with the things they buy like at some point, there are some products that are highly priced but posses a very low quality features. (relationship between price and product) 
Sentence-12 (P-5/S-12): We must pick those that are either low or medium priced products with high quality, that way we can say that we had the best offer products of our life. (recommendation for smart buying)

Discussion for Paragraph-5:

Paragraph-5 contains twelve sentences. Three sentences are comments on price unfairness (P$5 / \mathrm{S}-1),(\mathrm{P}-5 / \mathrm{S}-3)$ and $(\mathrm{P}-5 / \mathrm{S}-4)$. Those are followed by participant's suggestions for smart buying (P-5/S-7) and (P-5/S-12). The various direction of relationship between price and product quality is mentioned (P-5/S-10) and (P-5/S-11). P-5/S-8 and P-5/S-5 show her choice for low price product does not seem to be the best decision in comparison with her personal experience for smart buying $(\mathrm{P}-5 / \mathrm{S}-9)$.

The author summarizes the above sentencial analysis by developing the following Table of Expressions. Price decision is categorized into two motives of benefit. Category-1 contains expressions of justification for choosing lower price i.e. lower price for internal motives of benefit (see Table-1). Category-2 contains expressions of justification for not choosing higher price (see Table-2). In Category-2, participant justifies that her price decision is considered as the best decision. In addition, critical comments/expressions in Category- 2 are made by participant to conclude her decision as "socially" correct and highly recommended. Category2 is also considered as rejection, concealment or camouflage to justify Category-1. Expressions of acceptance in price and quality relationship are also provided (see Table-3).

Table-1

Expressions - Internal motives of benefit for price decision (Category-1)

*) p.a. = physical appearance performance ; o.v. = overall performance ; s.c. $=$ social performance

Lower price for Internal motives of benefit

1) simple metallic casing (p.a, P-1/S-9)

2) it looked cute and was very colorful (p.a., P-1/S-10)

3) the designs looked so elegant and neat (p.a., P-1/S-11)

4) It was a good bargain (o.v., P-1/S-13)

5) It had great attractive designs (p.a.,P-2/S-5)

6) it just looked the same (o.v.,P-3/S-2)

7) I was happy to have the product (o.v.,P-3/S-3)

8) just a copy but it says it all (o.v.,P-3/S-4)

9) the same quality as the original product (o.v., P-3/S-5)

10) Really, you couldn't tell the difference (o.v.,P-3/S-6)

11) a benefit for me more than a cost (o.v.,P-3/S-7)

12) cute and looked attractive (p.a.,P-3/S-8)

13) It had great designs (p.a.,P-3/S-9)

14) still look like an original (o.v.,P-3/S-11)

15) I got the benefit (o.v.,P-3/S-12)

16) it would last long (o.v.,P-3/S-13)

17) It looks exactly the same (o.v.,P-4/S-5)

18) people should be smart (s.c.,P-4/S-8) 
Table-2

Expressions - Rejection (Category-2)

Higher price unfairness

1) I realized that maybe they are over pricing it (P-4/S-1)

2) should not cost that much $(\mathrm{P}-4 / \mathrm{S}-2)$

3) That is just ridiculous (P-4/S-3)

4) meant to be bargained (P-4/S-6)

5) Some things are overpriced (P-4/S-7)

6) shouldn't cost us that much (P-4/S-9)

7) should adjust their prices fairly and right (P-4/S-11)

8) store owners to be more fair (P-5/S-1)

9) never right (P-5/S-3)

10) adjust their prices fairly (P-5/S-4)

11) I recommend high quality products $(\mathrm{P}-5 / \mathrm{S}-5)$

12) recommend people to be thorough $(\mathrm{P}-5 / \mathrm{S}-7)$

13) wise in picking out low-priced-high quality products $(\mathrm{P}-5 / \mathrm{S}-8)$

14) highly priced but posses a very low quality (P-5/S-11)

Table-3

Expressions - Acceptance

Price and quality relationship

Low price for low quality

1) looked like an original (P-2/S-2)

2) just a copy but it says it all (P-3/S-4)

3) Some low-priced products are also low quality products $(\mathrm{P}-5 / \mathrm{S}-10)$

Analysis of respondents' responses on the relationship between price and product quality

The author uses quantitative approach to measure respondents' strength of tendency for low price regime (belief strength in savings benefit) and high price regime (belief strength in social benefit). There are 64 respondents participated in this research. They are required to give response using five Likert-scales ( $1=$ strongly disagree ; $2=$ disagree ; $3=$ uncertain ; 4 $=$ agree $; 5=$ strongly agree) on the following statements: (1) Price always has connection with product quality (p_pq1); (2) Price is more important than product quality (p_pq2); (3) High quality is always followed by high price (hq_hp); (4) What I need is high quality with low price (hq_lp).

Data is analyzed using SPSS Ver. 17. One-sample t-test is employed to measure strength of tendency for low price regime (belief strength in savings benefit) and high price regime (belief strength in social benefit). Output of SPSS is interpretated. An integrated qualitativequantitative discussion is made. 
In low price regime, price becomes major orientation for savings benefit. Relationship between price and product quality can be negative i.e. low price for high quality product. Tendency for the highest degree of belief strength happens in the following indicators: (Indicator-1) when p_pq1 (price always has connection with product quality) is closer to 1 (=strongly disagree); (Indicator-2) when p_pq2 (price is more important than product quality) is closer to 5 (=strongly agree); (Indicator-3) when hq_hp (high quality is always followed by high price) is closer to 1 (=strongly disagree); and (Indicator-4) when hq_lp (what I need is high quality with low price) is closer to 5 (=strongly agree).

In high price regime, price is the main reason for social benefit as long as it is consistently connected with product quality. Relationship between price and product quality usually positive i.e. high price for high quality product. It is also with the assumption that high quality product can be beneficial for social acceptance. Tendency for the highest degree of belief strength happens in the following indicators: (Indicator-1) when p_pq1 (price always has connection with product quality) is closer to 5 (=strongly agree); (Indicator-2) when p_pq2 (price is more important than product quality) is closer to 1 (=strongly disagree); (Indicator-3) when hq_hp (high quality is always followed by high price) is closer to 5 (=strongly agree); and (Indicator-4) when hq_lp (what I need is high quality with low price) is closer to 1 (=strongly disagree).

\section{Low price regime}

1. Belief strength in savings benefit with Indicator-1 i.e. when p_pq1 (price always has connection with product quality) is closer to 1 (=strongly disagree)

Table-4.1 .1

One-sample statistics

Belief strength in savings benefit with Indicator-1

One-Sample Statistics

\begin{tabular}{|c|c|c|c|c|}
\hline & $\mathrm{N}$ & Mean & Std. Deviation & Std. Error Mean \\
\hline price $=$ quality & 64 & 4.36 & .880 & .110 \\
\hline
\end{tabular}

Table-4.1.2

One sample test (test value $=1$ )

Belief strength in savings benefit with Indicator-1

One-Sample Test

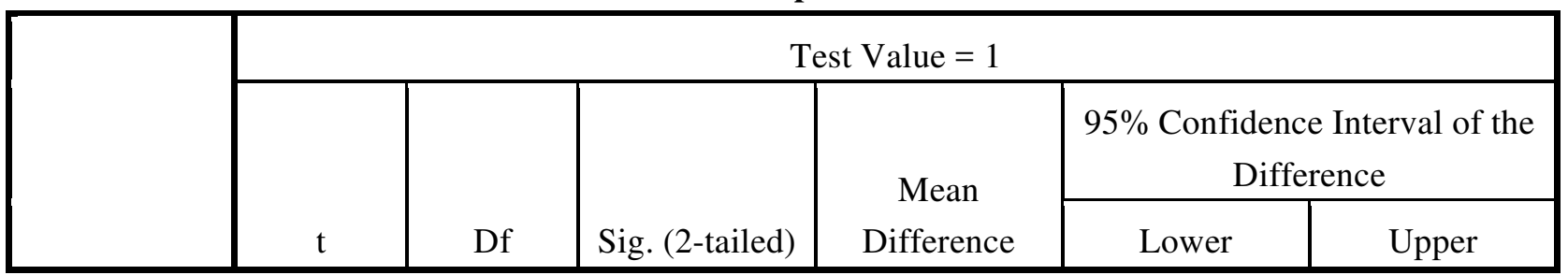


One-Sample Test

\begin{tabular}{|c|c|c|c|c|c|c|}
\hline & \multicolumn{6}{|c|}{ Test Value $=1$} \\
\hline & \multirow[b]{2}{*}{$\mathrm{t}$} & \multirow[b]{2}{*}{ Df } & \multirow[b]{2}{*}{ Sig. (2-tailed) } & \multirow{2}{*}{$\begin{array}{c}\text { Mean } \\
\text { Difference }\end{array}$} & \multicolumn{2}{|c|}{$\begin{array}{l}\text { 95\% Confidence Interval of the } \\
\text { Difference }\end{array}$} \\
\hline & & & & & Lower & Upper \\
\hline price $=$ quality & 30.556 & 63 & .000 & 3.359 & 3.14 & 3.58 \\
\hline
\end{tabular}

Mean difference from the belief strength point $(1=$ strongly disagree $)$ is accounted for 3.359. The value of 1 (=strongly disagree) is significantly different with 4.36 at 0.000 (very significant). Respondents agree (mean $=4.36$ ) that price always has connection with product quality. The result shows that there is no belief strength.

2. Belief strength in savings benefit with Indicator-2 i.e. when p_pq2 (price is more important than product quality) is closer to 5 (=strongly agree)

Table-4.2.1

One-sample statistics

Belief strength in savings benefit with Indicator-2

One-Sample Statistics

\begin{tabular}{|c|c|c|c|c|}
\hline & $\mathrm{N}$ & Mean & Std. Deviation & Std. Error Mean \\
\hline price $>$ quality & 64 & 1.88 & .984 & .123 \\
\hline
\end{tabular}

Table-4.2.2

One sample test (test value $=5$ )

Belief strength in savings benefit with Indicator-2

One-Sample Test

\begin{tabular}{|c|c|c|c|c|c|c|}
\hline & \multicolumn{6}{|c|}{ Test Value $=5$} \\
\hline & \multirow[b]{2}{*}{$\mathrm{t}$} & \multirow[b]{2}{*}{ Df } & \multirow[b]{2}{*}{ Sig. (2-tailed) } & \multirow{2}{*}{$\begin{array}{c}\text { Mean } \\
\text { Difference }\end{array}$} & \multicolumn{2}{|c|}{$\begin{array}{l}\text { 95\% Confidence Interval of the } \\
\text { Difference }\end{array}$} \\
\hline & & & & & Lower & Upper \\
\hline price $>$ quality & -25.407 & 63 & .000 & -3.125 & -3.37 & -2.88 \\
\hline
\end{tabular}

Mean difference from the belief strength point $(5=$ strongly agree $)$ is accounted for -3.125 . The value of 5 (=strongly agree) is significantly different with 1.88 at 0.000 (very 
significant). Respondents tend to disagree (mean $=1.88$ ) that price is more important than product quality. The result shows that there is no belief strength.

3. Belief strength in savings benefit with Indicator-3 i.e. when hq_hp (high quality is always followed by high price) is closer to 1 (=strongly disagree)

Table-4.3 .1

One-sample statistics

Belief strength in savings benefit with Indicator-3

\section{One-Sample Statistics}

\begin{tabular}{|c|c|c|c|c|}
\hline & $\mathrm{N}$ & Mean & Std. Deviation & Std. Error Mean \\
\hline h_quality=h_price & 64 & 3.59 & .971 & .121 \\
\hline
\end{tabular}

Table-4.3.2

One sample test (test value $=1$ )

Belief strength in savings benefit with Indicator-3

One-Sample Test

\begin{tabular}{|c|c|c|c|c|c|c|}
\hline & \multicolumn{6}{|c|}{ Test Value $=1$} \\
\hline & \multirow[b]{2}{*}{$\mathrm{t}$} & \multirow[b]{2}{*}{ Df } & \multirow[b]{2}{*}{ Sig. (2-tailed) } & \multirow{2}{*}{$\begin{array}{c}\text { Mean } \\
\text { Difference }\end{array}$} & \multicolumn{2}{|c|}{$\begin{array}{c}95 \% \text { Confidence Interval of the } \\
\text { Difference }\end{array}$} \\
\hline & & & & & Lower & Upper \\
\hline h_quality=h_price & 21.363 & 63 & .000 & 2.594 & 2.35 & 2.84 \\
\hline
\end{tabular}

Mean difference from the belief strength point $(1=$ strongly disagree $)$ is accounted for 2.594 . The value of 1 (=strongly disagree) is significantly different with 3.59 at 0.000 (very significant). Respondents tend to agree (mean $=3.59$ ) that high quality is always followed by high price. The result shows that there is no belief strength.

4. Belief strength in savings benefit with Indicator-4 i.e. when hq_lp (what I need is high quality with low price) is closer to 5 (=strongly agree)

Table-4.4 .1

One-sample statistics

Belief strength in savings benefit with Indicator-4 


\begin{tabular}{|c|c|c|c|c|}
\hline \multicolumn{5}{|c|}{ One-Sample Statistics } \\
\hline & $\mathrm{N}$ & Mean & Std. Deviation & $\begin{array}{l}\text { Std. Error } \\
\text { Mean }\end{array}$ \\
\hline i need hq_lp & 64 & 4.31 & .889 & .111 \\
\hline
\end{tabular}

Table-4.4.2

One sample test (test value $=5$ )

Belief strength in savings benefit with Indicator-4

One-Sample Test

\begin{tabular}{|c|c|c|c|c|c|c|}
\hline & \multicolumn{6}{|c|}{ Test Value $=5$} \\
\hline & \multirow[b]{2}{*}{$\mathrm{t}$} & \multirow[b]{2}{*}{ Df } & \multirow[b]{2}{*}{ Sig. (2-tailed) } & \multirow{2}{*}{$\begin{array}{c}\text { Mean } \\
\text { Difference }\end{array}$} & \multicolumn{2}{|c|}{$\begin{array}{c}\text { 95\% Confidence Interval of the } \\
\text { Difference }\end{array}$} \\
\hline & & & & & Lower & Upper \\
\hline i need hq_lp & -6.189 & 63 & .000 & -.688 & -.91 & -.47 \\
\hline
\end{tabular}

Mean difference from the belief strength point ( $5=$ strongly agree $)$ is accounted for -0.688 . It means the mean value of 4.31 (=agree) is relatively close to 5 (=strongly agree). The value of 5 (=strongly agree) is significantly different with 4.31 at 0.000 (very significant), but the mean difference is low. Respondents tend to agree $($ mean $=4.31)$ that price is more important than product quality. The result shows that there is a potential belief strength indicated by the lower value of mean difference.

\section{High price regime}

1. Belief strength in social benefit with Indicator-1 i.e. when p_pq1 (price always has connection with product quality) is closer to 5 (=strongly agree)

Table-4.5 .1

One-sample statistics

Belief strength in social benefit with Indicator-1

\section{One-Sample Statistics}

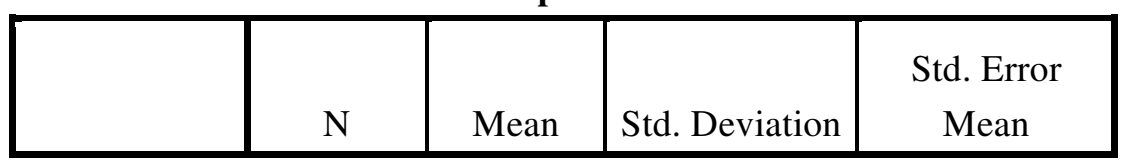


One-Sample Statistics

\begin{tabular}{|c|c|c|c|c|}
\hline & $\mathrm{N}$ & Mean & Std. Deviation & $\begin{array}{l}\text { Std. Error } \\
\text { Mean }\end{array}$ \\
\hline price $=$ quality & 64 & 4.36 & .880 & .110 \\
\hline
\end{tabular}

Table-4.5.2

One sample test (test value $=5$ )

Belief strength in social benefit with Indicator-1

One-Sample Test

\begin{tabular}{|c|c|c|c|c|c|c|}
\hline & \multicolumn{6}{|c|}{ Test Value $=5$} \\
\hline & \multirow[b]{2}{*}{$\mathrm{t}$} & \multirow[b]{2}{*}{ df } & \multirow[b]{2}{*}{ Sig. (2-tailed) } & \multirow{2}{*}{$\begin{array}{c}\text { Mean } \\
\text { Difference }\end{array}$} & \multicolumn{2}{|c|}{$\begin{array}{c}95 \% \text { Confidence Interval of the } \\
\text { Difference }\end{array}$} \\
\hline & & & & & Lower & Upper \\
\hline price $=$ quality & -5.827 & 63 & .000 & -.641 & -.86 & -.42 \\
\hline
\end{tabular}

Mean difference from the belief strength point $(5=$ strongly agree $)$ is accounted for -0.641 . The mean value of 4.36 is closer to 5 . The value of 5 (=strongly agree) is significantly different with 4.36 at 0.000 (very significant), but the mean difference is relatively low. Respondents tend to agree (mean $=4.36$ ) that price is more important than product quality. The result shows that there is a potential belief strength indicated by the lower value of mean difference.

2. Belief strength in social benefit with Indicator-2 i.e. when p_pq2 (price is more important than product quality) is closer to 1 (=strongly disagree)

Table-4.6.1

One-sample statistics

Belief strength in social benefit with Indicator-2

\section{One-Sample Statistics}




\begin{tabular}{|c|c|c|c|c|}
\hline & $\mathrm{N}$ & Mean & Std. Deviation & $\begin{array}{l}\text { Std. Error } \\
\text { Mean }\end{array}$ \\
\hline price $>$ quality & 64 & 1.88 & .984 & .123 \\
\hline
\end{tabular}

Table-4.6.2

One sample test (test value $=1$ )

Belief strength in social benefit with Indicator-2

\section{One-Sample Test}

\begin{tabular}{|c|c|c|c|c|c|c|}
\hline & \multicolumn{6}{|c|}{ Test Value $=1$} \\
\hline & \multirow[b]{2}{*}{$\mathrm{t}$} & \multirow[b]{2}{*}{ df } & \multirow[b]{2}{*}{ Sig. (2-tailed) } & \multirow{2}{*}{$\begin{array}{c}\text { Mean } \\
\text { Difference }\end{array}$} & \multicolumn{2}{|c|}{$\begin{array}{c}\text { 95\% Confidence Interval of the } \\
\text { Difference }\end{array}$} \\
\hline & & & & & Lower & Upper \\
\hline price $>$ quality & 7.114 & 63 & .000 & .875 & .63 & 1.12 \\
\hline
\end{tabular}

Mean difference from the belief strength point $(1=$ strongly disagree $)$ is accounted for 0.875 . The mean value of 1.88 is closer to 1 . The value of 1 (=strongly disagree) is significantly different with 1.88 at 0.000 (very significant), but the mean difference is relatively low. Respondents tend to disagree (mean $=1.88$ ) that price is more important than product quality. The result shows that there is a potential belief strength indicated by the lower value of mean difference.

3. Belief strength in social benefit with Indicator-3 i.e. when hq_hp (high quality is always followed by high price) is closer to 5 (=strongly agree)

Table-4.7.1

One-sample statistics

Belief strength in social benefit with Indicator-3

One-Sample Statistics

\begin{tabular}{|l|r|r|r|r|}
\hline & N & Mean & Std. Deviation & \multicolumn{2}{c|}{$\begin{array}{c}\text { Std. Error } \\
\text { Mean }\end{array}$} \\
\hline h_quality=h_price & 64 & 3.59 & .971 & .121 \\
\hline
\end{tabular}

Table-4.7.2

One sample test (test value $=5$ )

Belief strength in social benefit with Indicator-3 


\begin{tabular}{|c|c|c|c|c|c|c|}
\hline & \multicolumn{6}{|c|}{ Test Value $=5$} \\
\hline & \multirow[b]{2}{*}{$\mathrm{t}$} & \multirow[b]{2}{*}{ Df } & \multirow[b]{2}{*}{ Sig. (2-tailed) } & \multirow{2}{*}{$\begin{array}{c}\text { Mean } \\
\text { Difference }\end{array}$} & \multicolumn{2}{|c|}{$\begin{array}{c}\text { 95\% Confidence Interval of the } \\
\text { Difference } \\
\end{array}$} \\
\hline & & & & & Lower & Upper \\
\hline h_quality=h_price & -11.582 & 63 & .000 & -1.406 & -1.65 & -1.16 \\
\hline
\end{tabular}

Table-4.7.3

One sample test (test value $=3$ )

Belief strength in social benefit with Indicator-3

One-Sample Test

\begin{tabular}{|c|c|c|c|c|c|c|}
\hline & \multicolumn{6}{|c|}{ Test Value $=3$} \\
\hline & \multirow[b]{2}{*}{$\mathrm{t}$} & \multirow[b]{2}{*}{ Df } & \multirow[b]{2}{*}{ Sig. (2-tailed) } & \multirow{2}{*}{$\begin{array}{c}\text { Mean } \\
\text { Difference }\end{array}$} & \multicolumn{2}{|c|}{$\begin{array}{c}95 \% \text { Confidence Interval of the } \\
\text { Difference }\end{array}$} \\
\hline & & & & & Lower & Upper \\
\hline h_quality=h_price & 4.890 & 63 & .000 & .594 & .35 & .84 \\
\hline
\end{tabular}

Table-4.7.4

One sample test (test value $=4$ )

Belief strength in social benefit with Indicator-3

One-Sample Test

\begin{tabular}{|c|c|c|c|c|c|c|}
\hline & \multicolumn{6}{|c|}{ Test Value $=4$} \\
\hline & \multirow[b]{2}{*}{$\mathrm{t}$} & \multirow[b]{2}{*}{ Df } & \multirow[b]{2}{*}{ Sig. (2-tailed) } & \multirow{2}{*}{$\begin{array}{c}\text { Mean } \\
\text { Difference }\end{array}$} & \multicolumn{2}{|c|}{$\begin{array}{c}95 \% \text { Confidence Interval of the } \\
\text { Difference } \\
\end{array}$} \\
\hline & & & & & Lower & Upper \\
\hline h_quality=h_price & -3.346 & 63 & .001 & -.406 & -.65 & -.16 \\
\hline
\end{tabular}

Mean difference from the belief strength point $(5=$ strongly agree $)$ is accounted for -1.406 . The value of 5 (=strongly agree) is significantly different with 3.59 at 0.000 (very significant). Output from SPSS shows mean difference for test value $3(0.594)$ is greater than mean difference for test value 4 (-0.406). Mean value 3.59 is closer to 4 . Respondents agree 
( $4=$ agree) that high quality is always followed by high price. The result shows that there is potential belief strength.

4. Belief strength in social benefit with Indicator-4 i.e. when hq_lp (what I need is high quality with low price) is closer to 1 (=strongly disagree)

Table-4.8.1

One-sample statistics

Belief strength in social benefit with Indicator-4

One-Sample Statistics

\begin{tabular}{|c|c|c|c|c|}
\hline & $\mathrm{N}$ & Mean & Std. Deviation & $\begin{array}{l}\text { Std. Error } \\
\text { Mean }\end{array}$ \\
\hline i need hq_lp & 64 & 4.31 & .889 & .111 \\
\hline
\end{tabular}

Table-4.8.2

One sample test (test value $=1$ )

Belief strength in social benefit with Indicator-4

One-Sample Test

\begin{tabular}{|c|c|c|c|c|c|c|}
\hline & \multicolumn{6}{|c|}{ Test Value $=1$} \\
\hline & \multirow[b]{2}{*}{$\mathrm{t}$} & \multirow[b]{2}{*}{$\mathrm{df}$} & \multirow[b]{2}{*}{ Sig. (2-tailed) } & \multirow{2}{*}{$\begin{array}{c}\text { Mean } \\
\text { Difference }\end{array}$} & \multicolumn{2}{|c|}{$\begin{array}{c}95 \% \text { Confidence Interval of the } \\
\text { Difference }\end{array}$} \\
\hline & & & & & Lower & Upper \\
\hline i need hq_lp & 29.821 & 63 & .000 & 3.313 & 3.09 & 3.53 \\
\hline
\end{tabular}

Mean difference from the belief strength point $(1=$ strongly disagree $)$ is accounted for 3.313. The value of 1 (=strongly disagree) is significantly different with 4.31 at 0.000 (very significant). Respondents tend to agree (sample mean value $=4.31$ ) with the statement "what I need is high quality with low price". The result shows that there is no belief strength.

Table-5

Belief strength in low price regime

*) t.v. = test value ; m.d. = mean difference

Indicator-1 : No belief strength (t.v. $=1 ;$ m.d. $=3.359)$

Indicator-2 : No belief strength (t.v. $=5 ;$ m.d. $=-3.125)$

Indicator-3 : No belief strength (t.v. $=1 ;$ m.d. $=2.599)$ 
Indicator-4 : Belief strength may potentially happen (t.v. $=5 ;$ m.d. $=-0.688)$

Table-6

Belief strength in high price regime

*) t.v. = test value; m.d. = mean difference

$\begin{array}{ll}\text { Indicator-1 } & \text { : Belief strength may potentially happen (t.v. }=5 ; \text { m.d. }=-0.641) \\ \text { Indicator-2 } & \text { : Belief strength may potentially happen (t.v. }=1 ; \text { m.d. }=0.875) \\ \text { Indicator-3 } & \text { : Belief strength may potentially happen (t.v. }=5 ; \text { m.d. }=-1.406) \\ \text { Indicator-4 } & \text { : No belief strength (t.v. }=1 ; \text { m.d. }=3.313)\end{array}$

Integrated qualitative-quantitative approach shows consumers' great favor on high quality low-price product which is not only in the level of expectation but also experience. There are 18 expressions of smart buying experience which are oriented to "cheap is the best" (see Table-1). There is also a high expectation for high quality low-priced product (see Table 4.4.1, 4.4.2 and 5). Meaning to say, belief strength in expectation for high quality low-priced product is contributed by experience of smart buying i.e. best effort to have good bargaining (see Table-1). It is a matter of effort and active participation to have the best (low) price.

Repetition of complimentary expression is made specially to appreciate physical appearance. There is an emotion of happiness and proud for the best low price buying decision which is validated by recommendation in "people should be smart (P-4/S-8)" (see Table-1). In Table-2 contains 14 expressions of high price unfairness. They are also considered as disagreement or rejection toward high price. This contradiction of emotion is found in Table-1 and Table-2. It is intended to justify, and at the same time, magnifying best decision to choose low-priced product, for example, it is not just "I was happy to have the product (P-3/S-3)" but also "should adjust their prices fairly and right (P-4/S-11)". In other words, the choice for lowpriced product is non-negotiable. It is a manifestation of "rights to have fair price" which corresponds with "rights to have cheap price". This has become truth. This non-negotiable truth is another representation for belief strength.

Paragraph and sentencial analysis have shown phenomena of struggling "a conflict" between tendency to favor the "attractiveness" of low price and accumulated rationality on "normative" positive price-quality relationship. From this perspective, responses of appreciation and rejection happen simultaneously. Appreciation and rejection happen at the same time. Product physical appearance has created "eye-catching" to drive responses of appreciation and rejection. Table-3 contains rationalization on the relationship between price and quality which is actually in positive direction i.e. low price for low quality and high price for high quality.

Tendency of high expectation on high quality product is shown by the potential belief strength in the statements "price always has connection with product quality" (see Indicator1 Table 4.5.1 and 4.5.2), "price is more important than product quality" (see Indicator-2 Table 4.6.1 and 4.6.2), and "high quality is always followed by high price" (see Indicator-3 Table 4.7.1 and 4.7.2). This belief strength reflects permanent knowledge resulted from 
accumulation of experience. In Table-6 there three indicators which are used so that belief strength can be accepted. This may indicate strong normative rules for the positive pricequality relationship. However, the essence is not this normative rules which are socially accepted but the potential belief strength of Indicator-4 "what I need is high quality with low price" (see Table-5).

From Table-1 it reveals the definition of high quality and low price in the context of high quality low-priced product. High quality specifically refers to physical appearance i.e. the design (elegant, neat, attractive, cute, great) and color (colorful). Quality is defined more on the product's performance to be perceived as the original product such as in "still look like an original (P-3/S-11)", and "It looks exactly the same (P-4/S-5)". Consequently, belief strength in "price is more important than product quality" (see Table 4.6.1, 4.6.2 and 6) can be in the frame of "fake" product acceptance (see Table-3).

Context of "high price" as in Indicator-3 "high quality is always followed by high price" (Table-4.7.1, 4.7.2, 4.7.3, 4.7.4 and Table-6) is accepted as long as it becomes high price unfairness (Table-2). It is a rejection as well as complete acceptance to favor lower price benefit.

\section{MANAGERIAL IMPLICATION}

Emotion in price consumption context could be essential specially to support the argument that it is not price matter (in this research is low-priced product) that has become "object of consumption" rather the ability of price to generate emotion and experience of thinking.

This research can measure how consumer expresses emotion through controversial price consumption experience i.e. price which is perceived irrationally. It is irrational when decision to favor low-priced product is considered as high-risk in which consumer accepts that low price corresponds to low quality but at the same time it is tolerable and feasible, even as the best choice.

It is not just low price but low price with emotional dimension. At this level, product seems to successfully accomodate experience of thinking and facilitate to reach rationality of low price - high quality. Product may attract consumer to think critically. Firms can gain insight from this perspective by developing substitute product. The substution might not be on the aspect of brand rather the functional value which is valid enough to represent the branded version. In other words, creating competitive products i.e. products with the same quality but different price is also recommended.

As perception is strongly influenced by past experience, it is necessary to create moment of truth when product is about to enter market. Product should create first impression in which it can produce ideas of reference i.e. having special personal meaning.

\section{CONCLUSION}

This research attempts to see dynamics of emotional dimension in low-priced product consumption experience using comparison among two price-benefit regimes i.e. "cheap is the best" and "expensive is the best". Terminology of belief strength is introduced to create better perspective on the dimension of emotion. It is used to see emotion as an extreme effort or totality in cognitive activity. 
Consumption experience is consumer's cognitive process for defining quality. It includes consumer's justification for low price which is at the expense of high price unfairness in high price regime. In other words, low price refers to high quality as long as high price is unfair. There is a critical thought in consumer's mind that in positive price-quality relationship, high price is considered as incorrect. The incorrect high price in positive price-quality relationship is also strongly supported by consumer's recommendation to be more careful and critical toward high price. In the environment of low price (low price regime), the social benefit of high price rejection is "I can show and certify that high price tends to be firm's incorrect and inappropriate decision". It is an expression of identity which has social value such as "I want to show you that I am doing something important for other people".

The author would like to extend suggestion for in-depth research to achieve instrument validity specially in the area of low-priced product consumption experience.(C)

\section{REFERENCES}

Becker, Gary S. (1976). The Economic Approach to Human Behavior. Chicago: The University of Chicago Press

Carson, David; Gilmore, Audrey; Perry, Chad and Gronhaug, Kjell (2001). Qualitative Marketing Research. London: Sage Publication

Fabrycky, W.J. Thuesen, G.J. and Verma, D. (1998). Economic Decision Analysis. New Jersey: Prentice-Hall Inc.

Gravetter, Frederick J. \& Forzano, Lori-Ann B (2009). Research Methods in Behavioral Sciences.USA: Wadsworth Cengage Learning

Krug, Ronald S. \& Cass, Aluah R (1989). Behavioral Sciences. New York: Springer-Verlag New York Inc.

Lechte, John (1994). Fifty Key Contemporary Thinkers. From Structuralism to Postmodernity. London: Routledge

Smith, Robert E. \& Swinyard, William R. (1982). Information Response Models: An Integrated Approach. Journal of Marketing Vol. 46 (Winter 1982) pp. 81-93

Wangsa, Ignasius H.S (2011). The Insights on Perceived Price-Quality. International Research Journal of Business Studies Vol. 4 No. 3 December 2011 - March 2012 pp. 229251 